Primljen / Received: 20.4.2012.

Ispravljen / Corrected: 4.9.2012.

Prihvaćen / Accepted: 2.10.2012.

Dostupno online / Available online: 15.11.2012.

\section{Numerical model of water infiltration into unsaturated medium}

\title{
Authors:
}

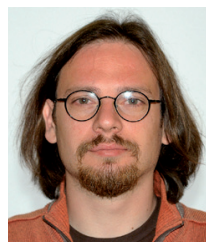

Asst.Prof. Vanja Travaš, PhD. CE

University of Rijeka

Faculty of Civil Engineering

vanjat@gradri.hr

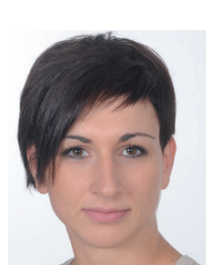

Ivana Lanča, B.Sc. CE

University of Rijeka

Faculty of Civil Engineering

ivana.lanca@gradri.hr

\section{Vanja Travaš, Ivana Lanča}

\section{Numerical model of water infiltration into unsaturated medium}

The one-dimensional model of vertical infiltration of water into an unsaturated soil layer is presented in the paper. The stationary boundary condition of constant soil surface watering is used for analysing the dynamics of transition from the unsaturated to saturated state of soil pores. The discretisation of the space and time domain of flow is conducted using the finite difference method. The resulting numerical algorithm is included in the program package MathCAD 14 to enable numerical analysis of filtration flow rate.

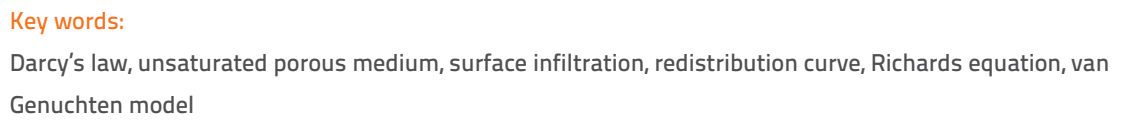

Pregledni rad

\section{Vanja Travaš, Ivana Lanča}

\section{Numerički model infiltracije vode u nesaturiranu sredinu}

U radu je prikazan numerički model vertikalne infiltracije vode u nesaturirani sloj tla. Da bi se spoznala dinamika prelaska iz nesaturiranog u saturirano stanje pora tla, u radu se koristi stacionarni rubni uvjet konstantnog natapanja površine tla. Diskretizacija prostorne i vremenske domene toka je provedena metodom konačnih razlika. U svrhu izrade numeričkih analiza filtracijskog toka, rezultirajući numerički algoritam je implementiran u programskom paketu MathCAD 14.

\section{Ključne riječi:}

Darcyjev zakon, nesaturirana porozna sredina, površinska infiltracija, redistribucijska krivulja, Richardsova jednadžba, van Genuchtenov model

Übersichtsarbeit

Vanja Travaš, Ivana Lanča

\section{Numerisches Modell der Wasserinfiltration in nicht saturiertes Milieu}

In der Arbeit wird ein numerisches 1D-Modell der vertikalen Wasserinfiltration in eine nichtsaturierte Bodenschicht dargestellt. Zum Zwecke der Betrachtung der Transitionsdynamik vom nicht saturierten zum saturierten Zustand der Bodenporen wird in der Arbeit die feststehende Randbedingung einer konstanten Berieselung der Bodenoberfläche verwendet. Die Diskretisierung der Zeit- und Raumdomäne des Flusses geschieht mithilfe der Finite-Differenzen-Methode. Zum Zwecke der Erstellung einer numerischen Analyse des Filtrationsverlaufs wird der sich ergebende numerische Algorithmus in das Programmpaket MathCAD 14 importiert.

\section{Schlüsselwörter:}

Darcy-Gesetz, nicht saturiertes, poröses Milieu, Oberflächeninfiltrierung, Redistributionskurve, RichardsGleichung, Van-Genuchten-Modell 


\section{Introduction}

Filtration flows can be operated through either saturated or unsaturated porous bodies, depending on the quantity of liquid in pores of an intergranular medium. In the water engineering practice, the role of liquid is most often assumed by water, while soil is the porous medium. At that, in order to conduct analyses of practical relevance, it is assumed, both in this paper and for other uses, that the flow of water in soil pores can be regarded "through" the continuum hypothesis, i.e. that the porosity of soil is such that its representative elementary volume can be defined [1].

If soil pores are completely filled with water, the contained water forms a continuous whole. In such circumstances, the disturbance in pressure field is transferred through space occupied with water. In other words, the difference in the levels of contained water will result in its movement. The description of such filtration flow is a part of elementary education of water engineers, and is based on the assumption that the value of turbulent motion can be neglected in relation to the value of the entire flow domain. The above justifies the use of the potential flow theory and, in this way, the modelling of filtration flow in saturated media is reduced to solving Laplace or Poisson differential equations. The choice of equation depends of whether the parameters of flow change during its analysis [2]. In unsaturated porous media, the flow of water is operated through the space that is either fully or partly filled with gas. For water flow through soil pores, the contained gas is always the air. The quantity of contained water must be quantified in order to define the rate at which soil pores are filled with water. For this purpose, we use the saturation degree $\theta$, which is defined by the ratio of water volume to a porous medium volume (1):

$\theta(x, y, z, t)=\frac{V_{\text {water }}}{V_{\text {medium }}}$

The theoretical saturation degree $\theta$ can range from zero (corresponding to the totally dried out porous medium) to full saturation, $\theta_{s^{\prime}}$ which defines the state of soil in which all pores are occupied with water. At that, it should be noted that the situation in which the soil is dried out to the level corresponding to $\theta=0$ can not be encountered in practice. This is due to the fact that a certain quantity of water, adhering to soil particles, is always found in soul because of relatively strong molecular forces acting between soil particle walls and water. This quantity of water can significantly influence the rate at which pores are filled in an unsaturated medium, and must therefore be taken into account. The degree of saturation corresponding to the mentioned quantity of water is called the residual degree of saturation qr (3) and, in case of soil, it most often ranges from 0,001 to 0,02.

It can easily be understood that each saturation of a medium is preceded by a certain time of an unsaturated condition. Consequently, the importance of describing unsaturated filtration flows actually results from design specifications in which the rate of transition between the saturated and unsaturated condition of soil (and vice versa) has to be defined. A classical example of this is the water flow through embankment realized for flood protection purposes [2]. In addition, a practical significance of unsaturated flow modelling for the design of soil improvement projects can easily be noticed. At that, unlike the above mentioned case, such filtration flow is operated in the direction of the gravitational force, through geological formations of soil that are most often parallel to each other and, at the same time, perpendicular to the flow of water. These conditions are almost always encountered in relatively shallow paedologic horizons where attempts are made to ensure conditions appropriate for enabling supply of nutrients to roots of various agricultural crops. In this way, and unlike the mentioned case of flow through embankment (where a curved water face reveals the presence of vertical and horizontal components of speed), the process of initiation of irrigation of agricultural areas is most often described as one dimensional filtration flow.

A numerical model or redistribution of saturation in soil, resulting from constant irrigation of soil surface, is presented in the paper. The model results in a scalar function $\theta(z, t)$ in which independent variables are: vertical coordinate of aquifer $z_{1}$ and time $t$ that has elapsed since the irrigation initiation moment. In literature, this function is known as the redistribution curve [4].

\section{Constitutive soil model}

As a small velocity of flow $v_{s}$ is typical for filtration flow in soil, the contribution of kinetic energy to the total energy of water can be neglected from the engineering point of view. Therefore, the piezometric potential $\mathrm{H}$ can be defined as follows:

$H=z+\frac{p}{\rho g}$

where $z$ is the geodetic level of water particle as compared to a reference level, $g$ is the gravity of earth, $\rho$ is the pressure, and the $p / \rho g$ ratio is the corresponding piezometric pressure head $h$. In these circumstances, the flow velocity $v_{s}$ in a porous element of the length $d l$ can be related to the difference in potential $\mathrm{dH}$ at its edges. This dependence is defined by the Darcy's law:

$v_{d}=k_{s} \frac{d H}{d l}$

where $v_{d}$ is Darcy's seepage velocity, and $k_{s}$ is the saturated coefficient of permeability in the dimension $[L / T]$. Knowing the effective porosity of material, a linear link between $v_{d}$ and $v_{s}$ can be established [5].

When filtration in unsaturated media is described, it is also necessary to define functional dependence between the 
filtration coefficient $k$ (which is the measure of flow capacity in porous medium), and the quantity of water in pores of a material $(\theta)$. In fact, if all pores are filled with water $\left(\theta=\theta_{s}\right)$, then the coefficient $k$ becomes equal to the coefficient $k_{s}$. For all other cases, i.e. for cases in which $\theta<\theta_{s^{\prime}}$ nonlinear dependence between $\theta$ and $k$ must be defined. The model is based on the generalized Darcy's law:

$v_{d}=k(\theta) \nabla H ; \nabla=\left(\frac{\partial}{\partial x}, \frac{\partial}{\partial y}, \frac{\partial}{\partial z}\right)$

and it defines the nonlinear functional dependence $k(\theta)$. As the filtration coefficient $k(\theta)$ can range from zero to $k_{s^{\prime}}$ the normalisation is introduced as follows:

$k(\theta)=k_{r}(S) k_{s} \quad ; \quad 0 \leq k_{r} \leq 1$

where $k_{r}$ is the relative filtration coefficient dependant on the relative level of saturation $S(6)$.

$S=\frac{\theta-\theta_{r}}{\theta_{s}-\theta_{r}} \quad ; \quad 0 \leq S \leq 1$

The constitutive modelling of soil is now reduced to an appropriate definition of the function $k_{r}(S)$. For that purpose, van Genuchten recommends [9]:

$k_{r}(S)=\sqrt{S}\left\lceil 1-\left(1-S^{\frac{1}{m}}\right)^{n}\right\rceil^{2}$

where $m$ and $n$ are dimensionless empirical soil parameters, conjugated to each other by the equation

$m=1-(1 / n) \quad$ za $\quad n>1$

Although it is difficult to interpret the real physical significance of parameter $n$, this dimensionless value is often explained as a calibration parameter that is used to describe distribution of pore sizes in a granular medium. In fact, Guber et al. [6] show that $n$ correlates with the volume proportion of a relatively small aggregate fraction.

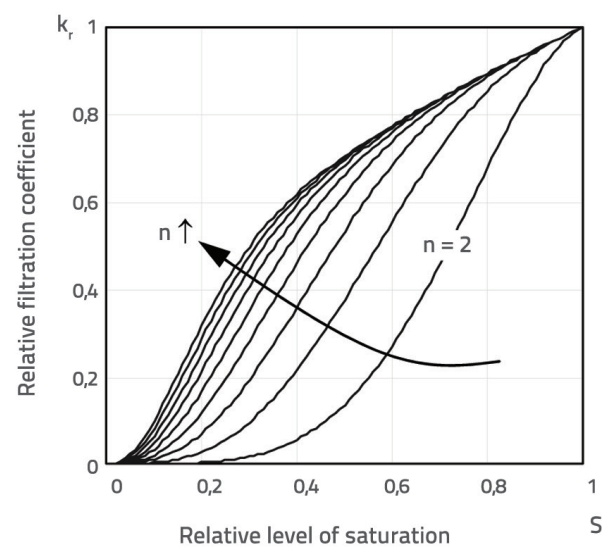

Figure 1. Increase of coefficient $k_{r}$ with an increase in coefficient $S$ (van Genuchten constitutive model)
The influence of parameter $n$ on the capacity of filtration through a porous medium is shown in Figure 1 via several curves defined by equation (7), obtained for parameters $n$ in the range from 2 to 10 (step $\Delta n=1$ ).

It is significant to note that the constitutive model (7) is valid only in case when saturation of a porous medium progressively increases over time, or stagnates around an achieved value. In fact, experiments have shown that hysteresis occurs in a constitutive relationship (7) [10]. If at some point in a porous medium the coefficient $S(6)$ starts to fall, the corresponding fall in coefficient filtration $k_{r}$ is not defined by the same constitutive law (7).

The modelling of hysteresis is needed in cases when the irrigation and drying of soil (or vice versa, or a cycle of these states) is expected within a time period under study. If soil irrigation is operated with a constant intensity, as is the case in this paper, the modelling of hysteresis is not required.

\section{Model of flow through an unsaturated medium}

The differential equation for filtration flow through unsaturated porous bodies is derived from the continuity equation written for a control volume within a porous medium. At that, if the space of such control volume can not be fully filled with water, the quantity of water present should be expressed by the level of saturation $\theta(1)$. If there is no spring or sinking within the control volume $V$, the time change of the contained mass of water will be equal to the difference of mass flow through the area of the control volume $A$ in the same period. In this way, if every differential element $d A$ of the area $A$ has a corresponding external normal $n$, the continuity equation can be written as follows [11]:

$\frac{\partial}{\partial t} \int_{V} \theta d V=\int_{A} \rho(\vec{V} \cdot \vec{n}) d A$

Using the Gauss's theorem, the right side of the equation (9) assumes the following form

$\int_{A} \rho(\vec{v} \cdot \vec{n}) d A=\int_{V} \nabla \cdot \rho \vec{v} d V$

and, as the flow of liquid under study can rightly be considered as an incompressible flow, the equation (10) can be written as follows

$\frac{\partial \theta}{\partial t}=\nabla v$

Using the Darcy's law (4), the preceding equation assumes the following form:

$\frac{\partial \theta}{\partial t}=\nabla[k(\theta) \nabla H]$

and, if the piezometric potential $H$ is written in the form defined by the equation (2), it can be concluded that:

$\frac{\partial \theta}{\partial t}=\frac{\partial}{\partial \mathbf{z}}\left(k(\theta)\left(\frac{\partial h}{\partial \mathbf{z}}+1\right)\right)$ 
The equation (13), known as the Richards equation, is the basic differential equation for flow of water through unsaturated porous media. As only several analytic solutions of Richards equations have so far been discovered, and as the solutions obtained are of small practical significance, the equation (13) is always solved numerically.

When defining the function $k(\theta)$, the equation (13) contains two unknowns, i.e. the unknown area of saturation, $\theta$ and the area of pressure height (head), $h$. In such circumstances the equation (13) can not be solved unambiguously. To counter this problem, new constitutive relationships are introduced and, in this way, the equation (13) can be rewritten in three different forms. The form presented in the paper (13) is known in literature as the $m$ form of Richards equation, and is not appropriate for definition of boundary conditions for constant irrigation of soil surface [7]. For that reason, an another form of equation is introduced, via a differential relationship:

$\frac{\partial \theta}{\partial t}=\frac{d \theta}{d h} \frac{\partial h}{\partial t}$

by means of which (13) can be presented as follows

$$
\frac{\partial h}{\partial t}=\frac{d h}{d \theta} \frac{\partial}{\partial z}\left(k(\theta)\left(\frac{\partial h}{\partial z}+1\right)\right)
$$

In equation (15), the term $d h / d \theta$ defines a unit change in pressure height of water that occurred due to simultaneous change of the degree of saturation $\theta$. In other words, the term $d h / d \theta$ is the reciprocal value of the harmonisation of porous medium $\mathrm{C}(\mathrm{h})$. Consequently, (15) can be written as follows

$\frac{\partial h}{\partial t}=\frac{1}{C(h)} \frac{\partial}{\partial \boldsymbol{z}}\left(k(\theta)\left(\frac{\partial h}{\partial \mathbf{z}}+1\right)\right)$

where

$$
C(h)=\frac{d \theta}{d h}
$$

As (17) describes a certain mechanical property of soil (that can be quantified in laboratory), the knowledge of the function (Ch) will results in a lower number of unknowns in (15) and, in this way, an unequivocal solution to the infiltration problem is defined. The equation (16) is known in literature as the form $h$ of the Richards equation [12]. In case the filtration flow is described by this equation, it should be noted that the boundary condition of the constant irrigation of soil surface should be defined in form of a pressure head $h$. For that purpose, the function $h(\theta)$ must be known. At that, the boundary condition for constant irrigation of soil surface can be defined in a simpler (more intuitive) way by specifying the degree of saturation as a boundary condition. In fact, in the time period $\mathrm{t}>\mathrm{t}_{0}$ the boundary condition $\theta=\theta_{\mathrm{s}}$ at the soil surface will define the state of constant irrigation. In order to obtain the form of equation (13) that would be appropriate for this purpose, the following equivalence is introduced $\frac{\partial h}{\partial z}=\frac{d h}{d \theta} \frac{\partial \theta}{\partial z}=\frac{1}{C(h)} \frac{\partial \theta}{\partial z}$

by means of which the form $h$ of the Richards equation (16) can be rewritten as

$\frac{\partial \theta}{\partial t}=\frac{\partial}{\partial z}\left(k(\theta)\left(\frac{1}{C(h)} \frac{\partial \theta}{\partial z}+1\right)\right)$

By arranging the equation (19) we obtain

$\frac{\partial \theta}{\partial t}=\frac{\partial}{\partial \boldsymbol{z}}\left(\frac{k(\theta)}{C(h)} \frac{\partial \theta}{\partial \boldsymbol{z}}+k(\theta)\right)$

where the ratio $k(\theta) / C(h)$ is most often interpreted as capillary diffusion $D(21)$ :

$D(\theta)=\frac{k(\theta)}{C(h)}$

As the capillary diffusion $D$ is explicitly dependent on the degree of saturation of porous medium q [13], the equation (20) can be reduced to the following form

$\frac{\partial \theta}{\partial t}=\frac{\partial}{\partial \boldsymbol{z}}\left(D(\theta) \frac{\partial \theta}{\partial \boldsymbol{z}}\right)+\frac{\partial \boldsymbol{k}(\theta)}{\partial \boldsymbol{z}}$

Once constitutive relationships (7) and (21) are defined, the equation (22) can be solved according to $\theta$. At that, it should be noted that in this case boundary conditions are also defined by specifying the value $\theta$. In other words, this last form of Richards equation (13) is the most favourable for modelling the time-and-space-related changes in the degree of saturation at constant irrigation of soil surface. It should be noted that the equation (17) defines the derivative at a point of the soil retention curve for a realized degree of saturation $\theta$. When approaching the full degree of saturation $\theta_{s^{\prime}}$ the ratio (17) approaches zero. At the moment when the complete soil saturation is realized, the $C(h)$ will be equal to zero. As shown in (21), the mentioned tendency will greatly influence the capillary diffusion $D$. Furthermore, at the moment when soil pores are completely filled with water, the diffusion becomes indeterminate (division with zero). During numerical calculation of the form $q$ of the Richards equation (22), this problem is noted much earlier, i.e. before the full soil saturation $\theta_{s}$ is achieved. For that reason, and because the boundary condition of constant irrigation (defined with $\theta_{s}$ ) is considered in the paper, the capillary diffusion $\mathrm{D}$ is adopted as a constant mechanical parameter [14]. In this way, the capillary diffusion D from (22) can be placed in front of the differential operator, and hence the following equivalence is established

$\frac{\partial \theta}{\partial t}=D \frac{\partial}{\partial \mathbf{z}}\left(\frac{\partial \theta}{\partial \mathbf{z}}+k(\theta)\right)$

The numerical algorithm, implemented using a high-level programming language MathCAD 14, is used for conducting numerical analyses related to the infiltration of water into 
a soil layer, and is based on a numerical approximation of solution obtained by equation (23).

\section{Discretisation of basic process equation}

Spatial discretisation of the flow domain is conducted from the soil surface, where $z=0$ (Figure 2), and is operated until a predefined depth of the water bearing layer is reached. The spatial step $\Delta z$ is adopted as constant. In this way, the spatial disposition of interesting variables is defined by the coordinate $i$, and their temporal position is defined by the coordinate $j$.
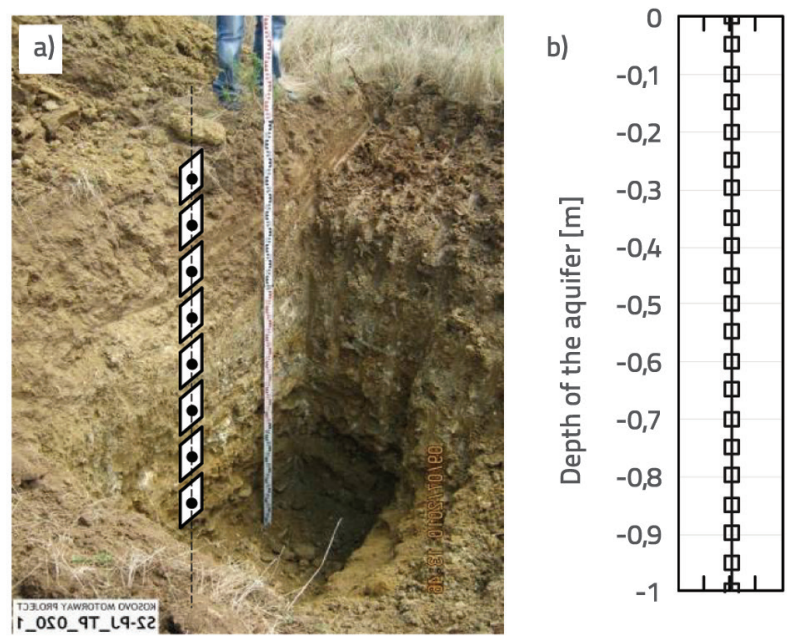

Figure 2. a) Soil profile and b) example of space discretisation between the soil surface and a permeable paedologic horizon

According to signs that have been introduced, the numerical approximation of partial derivative of a physical value $\cdot$ based on spatial coordinate $z$, assumes the following form:

$\frac{\partial "}{\partial z} \approx \frac{" j i+1}{\Delta z}$

a partial derivative of the same value in time becomes

$\frac{\partial "}{\partial t} \approx \frac{{ }_{i}^{j+1}-{ }_{i}^{j}}{\Delta t}$

It should be noted that the numerical discretisation of equation (22) also requires approximation of the second derivative of the degree of saturation q. In fact, the right hand side of the equation (22) contains the term

$\left\lceil\frac{\partial}{\partial z}\left(\frac{\partial \theta}{\partial z}\right)\right\rceil_{i}$

Using the approximation of the spatial derivative (24), the second derivative of the degree of saturation $q$ can be analogously approximated as follows:

$\frac{1}{\Delta z}\left[\left(\frac{\theta_{i+1}^{j}-\theta_{i}^{j}}{\Delta z}\right)-\left(\frac{\theta_{i}^{j}-\theta_{i-1}^{j}}{\Delta z}\right)\right]$
The numerical approximation will also require an approximation of the spatial derivative of the function $k(\theta)$ in (22). At that, as $k(\theta)$ can be interpreted as an indicator of water permeability between the two neighbouring layers of soil, the numerical approximation is most often conducted in a way that is somewhat different from the one defined with (24). In other words, in order to model the water permeability between two neighbouring layers near the discretisation point $i$, the filtration coefficient $k(\theta)$ is defined at a half of the spatial increment $D z$, and this as an average of the two neighbouring values $k(\theta)_{i-1}$ and $(\theta)_{i+1}$. The spatial change of the value $k(\theta)$ at point $i$ is defined using:

$k\left(\theta_{i+\frac{1}{2}}^{j}\right)=\frac{k\left(\theta_{i+1}^{j}\right)+k\left(\theta_{i}^{j}\right)}{2}$

and

$k\left(\theta_{i-\frac{1}{2}}^{j}\right)=\frac{k\left(\theta_{i}^{j}\right)+k\left(\theta_{i-1}^{j}\right)}{2}$

and so the derivative $\partial \mathrm{k}\left(\theta_{s}\right) / \partial \mathrm{z}$ in (22) is approximated as follows:

$\left.\frac{\partial k(\theta)}{\partial \boldsymbol{z}}\right|_{i} \approx \frac{k\left(\theta_{i+\frac{1}{2}}^{j}\right)-k\left(\theta_{i-\frac{1}{2}}^{j}\right)}{\Delta \boldsymbol{z}}$

If the studied soil segment is inhomogeneous, the numerical approximation of the equation (22) is conducted by attributing an appropriate value $k_{s}$ to each individual node $i$. Unlike the above mentioned case, the anisotropy modelling is far from trivial [15]. As one-dimensional vertical flow is considered in the paper, the anisotropy modelling is unnecessary (as there is only one component of velocity).

Using approximations of derivatives $(24,25,27,30)$, the equation (22) can be discretised and, after arrangement of terms, the following summarized numerical algorithm is defined:

$\frac{\theta_{i}^{j+1}-\theta_{i}^{j}}{\Delta t}=$

$\frac{\frac{D}{\Delta \boldsymbol{Z}}\left(\theta_{i+1}^{j}-2 \theta_{i}^{j}+\theta_{i-1}^{j}\right)}{\Delta \boldsymbol{Z}}+\frac{k\left(\theta_{i+\frac{1}{2}}^{j}\right)-k\left(\theta_{i-\frac{1}{2}}^{j}\right)}{\Delta \boldsymbol{Z}}$

For the known situation in time $j$, in each point $i$, the equation (31) defines $q$ in the following time interval $j+1$. At that, as $\theta^{j+1}$ is the only unknown in (31), the equation system obtained is explicit in time, which makes it highly attractive for use in calculation. Just like every other explicit numerical algorithm, this one is also subject to numerical stability criteria. In other words, for the selected spatial step $\Delta z$, the time step $\Delta$ t must meet the following inequality:

$\Delta t \leq \frac{(\Delta z)^{2}}{D} \delta \quad ; \quad \delta<1$

in which $\delta$ is the stabilization parameter. 

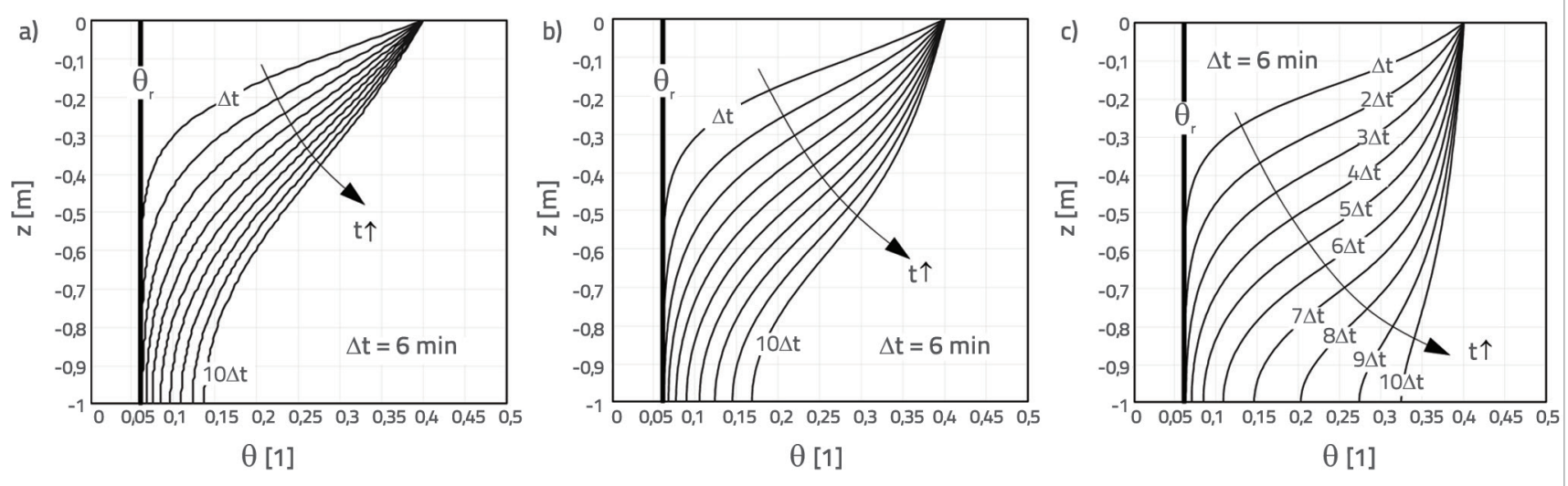

Figure 3. Redistribution curves: a) $k_{s}=1.5 \times 10^{-5} \mathrm{~m} / \mathrm{s}$; b) $k_{s}=3.75 \times 10^{-5} \mathrm{~m} / \mathrm{s}$; c) $k_{s}=7.5 \times 10^{-5} \mathrm{~m} / \mathrm{s}$

\section{Numerical analysis}

The numerical algorithm presented in the paper was used for the analysis of surface infiltration of water into a homogeneous soil layer. The equidistant spatial discretisation with 200 points was carried out from the ground surface at the level $z=0$, and was continued all the way down to $z=-1 \mathrm{~m}$. The redistribution of saturations was modelled within one hour. In order to present the progress of saturation, the diagrams contain several q curves, and this for time intervals $j \Delta t$, where $j=1 . .10$. The numerical analysis was made for soil with the following properties: $k_{s}=1.5 \times 10^{-5} \mathrm{~m} / \mathrm{s}$, $\theta_{r}=0.06 \mathrm{~cm}^{3} / \mathrm{cm}^{3}, \theta_{s}=0.4 \mathrm{~cm}^{3} / \mathrm{cm}^{3}, D=5 \times 10^{-5} \mathrm{~m}^{2} / \mathrm{s}$ and $n=$ 2. This is not a random selection of soil parameters. In fact, the parameters were selected with the purpose of defining soil that can realistically be categorized as loam [16] and, considering the quantity of vegetable soil and nutrients, loam is considered to be highly favourable for growing various agricultural crops. At that, in order to analyze influence of the coefficient $k_{s}$ on the development of the area $q$, the initial value $k_{s}$ was increased on two occasions by $\Delta k_{s}=2.25 \times 10^{-5} \mathrm{~m} / \mathrm{s}$ (the factor of increase amounts to 2.5). While not changing other constitutive parameters of soil, the tested range of coefficient $k_{s}$ can be interpreted as an attempt to describe the occurrence of crack in soil due to a longer period of drought. In fact, in this case the development of smaller, but also greater, cracks in soil will influence an increase in soil permeability. On the other hand, as the process of infiltration is here modelled in the scope of the continuum hypothesis, this will be reflected on the macroscopic level only through an increase in the coefficient $k_{s}$. Furthermore, to define the constant irrigation of soil surface, the Dirichlet boundary condition was defined in the node $\mathrm{i}=1$ with $\theta=\theta_{\mathrm{s}}=0.4 \mathrm{~cm}^{3} / \mathrm{cm}^{3}$. As it was agreed that the spatial discretisation ends at the permeable soil limit, the permeability condition $\theta_{n}=\theta_{n-1}$ (zero gradient boundary condition) was defined in the final node. Numerical analysis results are presented in Figure 3 . In all examples, the vertical line stands for the initial condition $\theta=\theta_{r}=0.06 \mathrm{~cm}^{3} / \mathrm{cm}^{3}$, i.e. for the area $\theta$ at the moment $t_{0}$.

The absorption capability of the porous medium increases with an increase in the value $k_{s^{\prime}}$ In fact, as shown in figure $3 c$, the redistribution curve is almost vertical in time $10 \Delta t$, which is an indication that, at that time, all soil pores are either saturated or are close to full saturation. Unlike the above mentioned (i.e. when $k_{s}$ is smaller), the Figure 3a shows the curve $\theta(z, 10 \Delta t)$, which reaches saturation of only $\theta=0.14$ for the same time at the bottom of the domain.
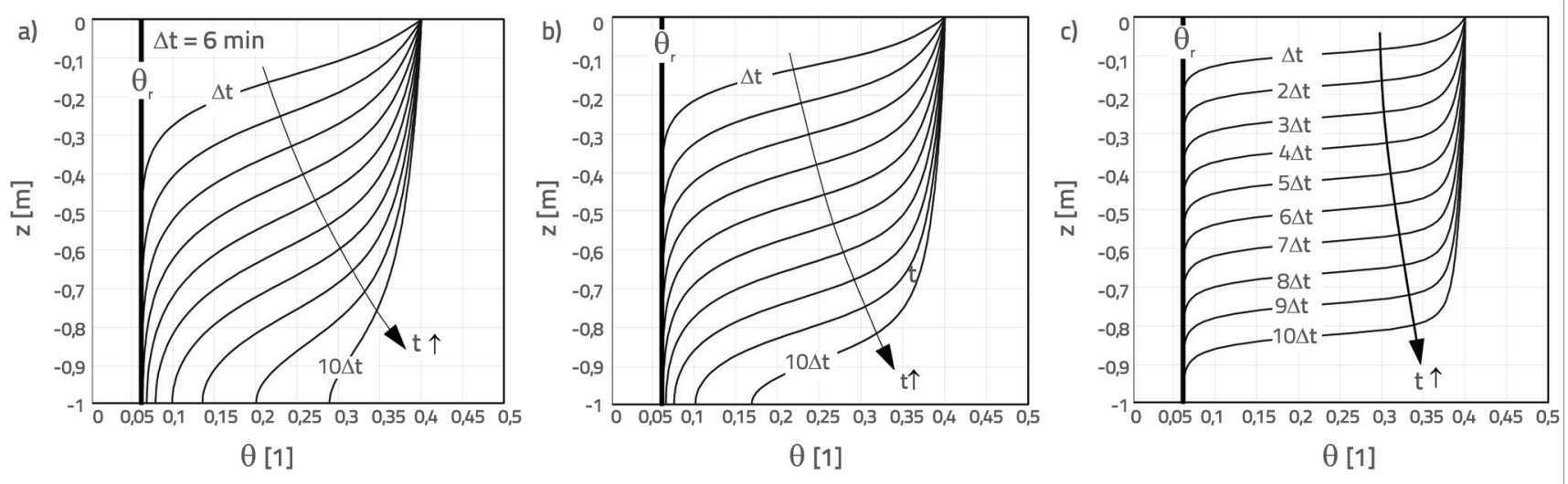

Figure 4. Redistribution curves for: a) $D=3.5 \times 10^{-5} \mathrm{~m}^{2} / \mathrm{s}$; b) $D=2.0 \times 10^{-5} \mathrm{~m}^{2} / \mathrm{s}$; c) $D=5.0 \times 10^{-6} \mathrm{~m}^{2} / \mathrm{s}$ 
It is also interesting to consider the water propagation mechanism in case when the capillary diffusion $D$ is smaller than the previously adopted one. The numerical analysis was conducted for three different values of $D$ in order to take into account the influence of $D$ on the development of the area $\theta(z, t)$. In addition to capillary diffusion $D$, which was reduced on three successive occasions for the increment of $\Delta D=1.5 \times 10^{-5} \mathrm{~m}^{2} / \mathrm{s}$, all other parameters remain constant and correspond to the last case of the previously presented numerical analysis (Figure 3c). Results of numerical analysis conducted for cases when the capillary diffusion $D$ assumes the value: $2.5 \times 10^{-6}, 1.25 \times 10^{-5}$ i $2.5 \times 10^{-5} \mathrm{~m}^{2} / \mathrm{s}$ (Figure 4.) are presented below.

As shown in Figure 4c, the segment of redistribution curve $\theta(z, t)$ in a relatively thin layer of flow domain is shaped almost horizontally for a relatively low value of the capillary diffusion D. In other words, the horizontal limit between the saturated and unsaturated medium (water front) is clearly shown. It should also be noted that the redistribution curve is defined only by its translation in time, in the case shown in Figure 4c. In fact, the shape of redistribution curve does not change in time for the adopted flow parameters, i.e. only the position of water front actually changes. On the other hand, by increasing the capillary diffusion $D$, Figures $4 \mathrm{a}$ and $4 \mathrm{~b}$ show contribution of capillary diffusion $D$ to the change in shape of redistribution curve, especially in later time intervals.

The numerical model also points to a negligible influence of the value $k_{s}$ on the change in shape and position of the redistribution curve in the time interval in which the water infiltration starts. For the adopted flow parameters, this time interval amounts to about $10 \mathrm{~min}(\sim 2 \Delta t)$. In fact, as shown in Figure 3, differences between all redistribution curves $\theta(z, \Delta t)$ are negligible, i.e. they are almost unnoticeable in time $\Delta t$, and this regardless of the size of the value $k_{s^{\prime}}$. The differences between curves start to be notable only after the time of about $2 \Delta t$ has elapsed (Figure 3 ). This development of distribution curve is the consequence of the constitutive soil model adopted (7). In fact, the change in filtration coefficient $k$ is almost negligible for small values of the degree of saturation $\theta$ (Figure 1). Considerable and sudden increase in the filtration coefficient $k$ is registered only after a certain degree of saturation $\mathrm{q}$ has been achieved. The coefficient $k$ development rate depends on the pore distribution parameter $n(7)$, i.e. on statistical distribution of pore sizes [6].

\section{Conclusion}

A numerical model of vertical infiltration of water into an unsaturated porous soil medium is presented in the paper. The boundary condition of constant soil surface irrigation is used to define and analyse the rate of transition from the unsaturated into saturated condition of soil pores. The spatial and temporal changes in the area $\theta(z, t)$ are defined by Richards equation for the zone between the water irrigation area and the bottom permeable limit of the flow domain. The spatial and temporal discretisation, based on the finite difference method, is conducted in order to find an approximate solution to the Richards equation. The explicit algorithm presented is implemented in the program package MathCAD 14 for purposes of the numerical flow analysis. The results obtained show changes in the area $\theta(z, t)$ in the period since the initial state of soil saturation, defined by residual degree of saturation $\theta_{r}$. The influence of the saturated filtration coefficient $k_{s}$ on the soil pore filing rate is analysed for the defined initial and boundary conditions. The numerical model also shows that the influence of the coefficient $k_{s}$ becomes important only after a certain time has elapsed since the moment $t_{0}$ in which irrigation of the soil surface starts. The influence of the capillary diffusion $D$, for the position and shape of redistribution curve in soil, is analysed in the same way. For that purpose, a case is presented in which the diffusion $D$ is sufficiently small to enable presentation of the limit between the saturated and unsaturated part of soil with a horizontal line. In other words, an interesting case of water infiltration is analysed (case characterized with two degrees of saturation only). The initial degree of saturation qr (residual degree of saturation), and full degree of saturation qs (defined at the ground surface), can be differentiated in this example. As shown in Figure 4c, the values for the flow conditions adopted are separated by a clear boundary. On the other hand, the influence of an additional increase in the capillary diffusion $D$ on the progress of the water front is also presented.

\section{REFERENCES}

[1] Bear, J.: Dynamics of Fluids in Porous Media, American Elsevier Publishing Company, New York, 1988.

[2] Gjetvaj, G.; Travaš, V.: Nasipi u hidromelioracionim radovima - Hidraulička analiza nestacionarnog tečenja kroz hidromelioracione nasipe, Priručnik za hidrotehničke melioracije: Elementi planiranja sustava za navodnjavanje, Rijeka, Liber, str. 77-130, 2005.
[3] Bronisz, C.L.; Hirt, C.W.: Unsaturated flow in porous media, Flow Science Inc., FSI-91-TN25R, 2005.

[4] Gopalakrishnan, K.; Manik, A.: A Mathematical Model for Predicting Isothermal Soil Moisture Profiles Using Finite Difference Method, International Journal of Computational and Mathematical Sciences, 2007. 
[5] Bear, J.: Hydraulics of Groundwater, McGraw-Hill International Book Co., 1979.

[6] Guber, A.; Pachepsky, Ya.; Shein, E.; Rawls, W.J.: Soil aggregates and water retention, Development of Pedotransfer Functions in Soil Hydrology (Eds Ya. Pachepsky, W.J. Rawls), Elsevier, 2004.

[7] Kumar, C.P.: Modelling of unsaturated flow, National Conference on "Modern Trends in Water Resources Development and Environmental Management", Vellore Institute of Technology, Vellore (Tamil Nadu), str. 1-9, 2002.

[8] Ožbolt, J.; Balabanić, G.; Kušter, M.: 3D Numerical modelling of steel corrosion in concrete structures, Corrosion Science, Volume 53, Issue 12, str. 4166-4177, 2011.

[9] van Genuchten, M. Th.: A colsed-form equation for predicting the hydraulic conductivity of unsaturated soils, Soil Science Society of America Journal, 44, str. 892$898,1980$.

[10] Klute. A.; Gillham, R.W.: An experimental study of soil water flow systems involving hysteresis, Environmental Resources Center, Colorado State University, Completion Report No. 51, 1973.
[11] Galvao, P.B.: Solute dynamics in unsaturated soil, Universidade Technica de Lisaboa, Intituto Superior Tecnico, No 44786, 2002.

[12] Phoon, K.; Tan, T.; Chong, P.: Numerical simulation of Richards equation in partially saturated porous media: under-relaxation and mass balance, Geotechnical and Geological Engineering, Volume 25, Number 5, 2007.

[13] Tzimopoulos, C.; Evangelides, C.; Arampatzis, G.; Anastasiadis E.: Water mass balance in the case of vertical infiltration, Global NEST Journal, Vol 7, No 3, str. 274-280, 2005.

[14] White, I.; Sully, M.J.: Macroscopic and microscopic capillary length and time scales from field infiltration, WaterResources Res., 23:str. 1514-1522, 1987.

[15] Zhu, J.; Sun, D.: Saturation-dependent anisotropy of unsaturated soil, World Congress of Soil Science, Soil Solutions for a Changing World, Brisbane, Australia, 2010.

[16] Aral, M. M.: Environmental Modeling and Health Risk Analysis (Acts/Risk), Springer-Verlag, 2010. 